\title{
A formação de professores $e$ as novas competências gerais propostas pela BNCC
}

\section{Teachertraining and the new general competences proposed by the BNCC - the Common National Curriculum Base}

Itale Cericato é Psicóloga, doutora em educação: psicologia da educação pela PUC-SP. Docente do Programa de Pós-graduação em Educação da Universidade Federal de São Paulo.

\section{Contato:italecericato@hotmail.com}

Lauri Cericato é Licenciado em filosofia e história. Pesquisador na área educacional e gestor de políticas públicas.

Contato: cericato.lauri@gmail.com

\section{Resumo}

Este artigo busca promover um debate sobre as competências gerais propostas pela Base Nacional Comum Curricular, aprovada pelo Conselho Nacional de Educação, e sobre possíveis caminhos para a formação de professores. Aponta-se para a necessidade da criação de uma agenda de discussão sobre modelos formativos ancorados em experiências que mobilizem leituras de mundo interdisciplinares, condizentes com o que se espera do professor no exercício de sua prática pedagógica para a formação das novas gerações. Sugere-se a exploração de recursos artísticos e culturais que ampliem o capital cultural dos professores, que, articulado aos demais saberes necessários para a atuação docente, favorece uma formação ativa, aberta, plural e conectada aos desafios contemporâneos.

Palavras-chave: Formação de professores. Prática pedagógica. Base Nacional Comum Curricular. Interdisciplinaridade. 


\begin{abstract}
This article aims to promote a debate about the general competences proposed by the CommonNational Curriculum Base, approved by the Ministry of Education and the possible paths for teacher training It points to the need to create adiscussion agenda on experience-based formative models, s which couldmobilize an interdisciplinary world understanding, consistent with what is expected from the teachers in their pedagogical practicesin order to form the new generations. It suggeststhe use of artistic and cultural resources that couldbroaden teachers' cultural capital which, along with the other necessary knowledge to teach, favoursan active, plural, and open training, connected to the contemporary challenges.

Key words: Teacher training. Pedagogical practice, Common National Curriculum Base. Interdisciplinarity
\end{abstract}

\title{
As competências gerais na formação de professores
}

\author{
Chegamos ao ponto em que temos de educar as pessoas naquilo que \\ ninguém sabia ontem, e prepará-las para aquilo que ninguém \\ sabe ainda, mas que alguns terão que saber amanhã.
}

(MEAD, 1968)

Neste artigo, busca-se promover um debate sobre as competências gerais propostas pela Base Nacional Comum Curricular (BNCC), aprovada em dezembro de 2017 pelo Conselho Nacional de Educação (CNE), e sobre possíveis caminhos para a formação de professores. Não nos propomos a discutir méritos ou complicadores para a educação nacional decorrentes da BNCC, porque a consideramos uma situação posta; cabendo, portanto, reflexões sobre como a formação de professores pode ser pensada a partir dela. Apresentamos, em um primeiro momento, as competências gerais propostas pela BNCC, abordando o que se compreende por competências. Esse conceito é discutido considerando-se uma necessária articulação com a formação dos professores que atuam na educação básica. Posteriormente, debatemos uma proposta formativa baseada em recursos artísticos e culturais que, ao contribuírem para a ampliação do capital cultural dos professores, estimulam a realização, por parte do profissional, de leituras de mundo interdisciplinares que embasem uma prática pedagógica capaz de oferecer respostas para as demandas da sociedade contemporânea. 


\section{Uma proposta de formação interdisciplinar}

A BNCC postula dez competências gerais que orientam os currículos das escolas de educação básica do Brasil. São elas: conhecimento; pensamento científico, crítico e criativo; senso estético; comunicação; argumentação; cultura digital; autogestão; autoconhecimento e autocuidado; empatia e cooperação; e autonomia. Segundo a BNCC, o conceito de competência é a mobilização de conhecimentos, habilidades, atitudes e valores para a resolução de demandas complexas da vida cotidiana, do pleno exercício da cidadania e do mundo do trabalho. Veja o infográfico:

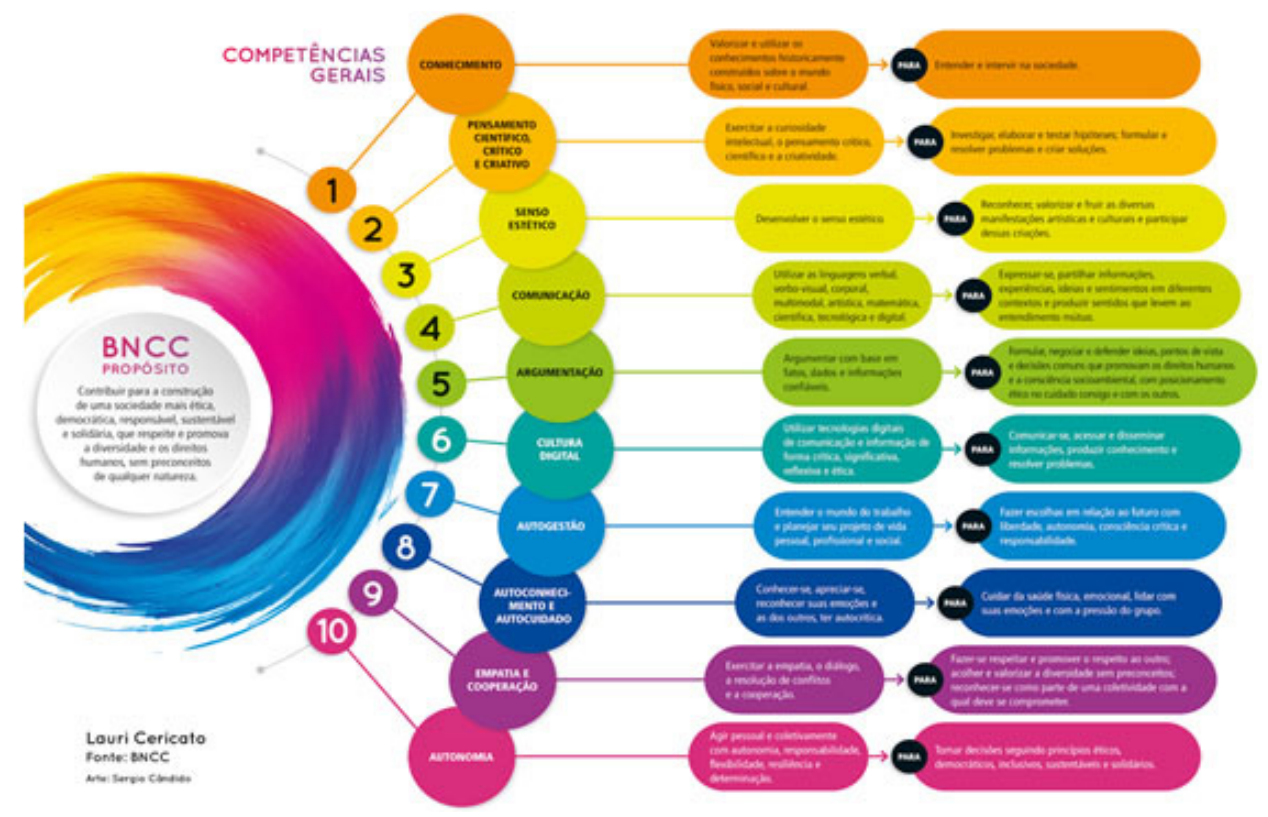

Figura 1: Infográfico explicativo das competências gerais contidas na BNCC.

A aprovação da BNCC reverberou em discussões sobre a formação dos professores. Em voga está o iminente lançamento pelo Ministério da Educação (MEC) de uma Base Nacional Comum Curricular para a formação do quadro docente que oriente os cursos de licenciatura, permitindo, plena e eficazmente, a implantação do currículo desejado nas escolas do país. No entanto, por detrás disso há uma antiga discussão: o que é formar o professor?

A formação de professores, para Cunha (2013), é um campo de estudos composto por tensões e compreensões subjetivas. Segundo a autora, a formação de professores se faz "em um continuum desde a educação familiar e cultural do professor até a sua trajetória formal e acadêmica, mantendo-se como processo vital enquanto acontece seu ciclo profissional" (CUNHA, 2013, p. 
612). Nóvoa (1992) afirma que o professor se forma como condição de sua mobilização para tal. Os estímulos e mediações que recebe são importantes; no entanto, precisam contar com o significado que o professor atribui à experiência formativa. Essa experiência é constituída pela trajetória de vida aliada aos referentes culturais e valores sociais que constituem o ser docente.

Macedo e Fini (2018) também falam em mobilização ao analisarem a definição de competência apresentada pela BNCC. Segundo os autores, esse vocábulo, relacionado ao verbo mobilizar, significa "pôr-se em movimento, mover, movimentar, pôr-se em ação ou em uso". Significa também "incitar à participação, motivar, impulsionar", ou seja, ações que põem algo em movimento. Assim, observam os autores, ser competente, de acordo com a BNCC, implica pôr ou se pôr em ação em seus diferentes sentidos:

\footnotetext{
Um professor que medeia pode ser diferente de um professor que mobiliza. Ele pode mobilizar de muitas formas: propor exercícios ou tarefas a serem realizados, configurar rodas de conversa sobre determinado tema, fazer reflexões ou propor projetos. 0 aluno, igualmente, pode ser mobilizado de muitas formas: pelas ações ou motivações de seu professor, pelo intercâmbio com seus pares, por suas motivações em fazer pesquisas, discutir um ponto de vista, assumir certa atitude ou abraçar dado valor. Quem mobiliza organiza uma situação, aceita um desafio, compromete-se com alguma coisa. A mobilização sempre acontece com um sujeito, mesmo que seja estimulada por outro. Se vida é movimento, viver é mobilizarse para the dar sentido, para conhecer e conviver com seus desafios. Daí competência ser, para a BNCC, o mesmo que conhecimento mobilizado, operado e aplicado em situação, sendo conhecimento compreendido de forma ampla, ou seja, envolvendo conceitos, procedimentos, valores e atitudes. (MACEDO; FINI, 2018, p. 15).
}

Mas como mobilizar as competências requeridas pela BNCC em processos de formação docente? Se é desejável que o professor proponha, a partir da BNCC, uma formação diferente aos seus estudantes, atenta às necessidades de um mundo em rápidas e constantes mudanças, é preciso oferecer para esse profissional uma formação também diferente, que supere os tradicionais modelos vigentes - em crise, como demonstrado por Gatti $(2010,2013)$-, nos quais disciplinas de educação se agregam ao currículo dos bacharelados na expectativa de que essa formação seja suficiente para o professor exercer seu trabalho. Contudo, dado o recorte temático proposto neste texto, se discutirá um aspecto específico dos saberes relativos à formação docente, que, 
articulado aos demais, parece oferecer interessante contribuição. Defende-se um modelo formativo de base cultural sólida, ancorado em experiências que favoreçam leituras de mundo interdisciplinares, assim como se deseja que isso também seja possível ao estudante. Não se trata de uma formação cultural simplista ou conteudista, que se esgota no acúmulo de informação, mas, sim, uma formação que permita conectar, significar e pôr em movimento, de modo múltiplo e variado e a partir da história de vida de cada indivíduo, o conhecimento acumulado pela história da humanidade. Em Barthes (1998), se encontra apoio para esse modelo, quando o autor afirma:

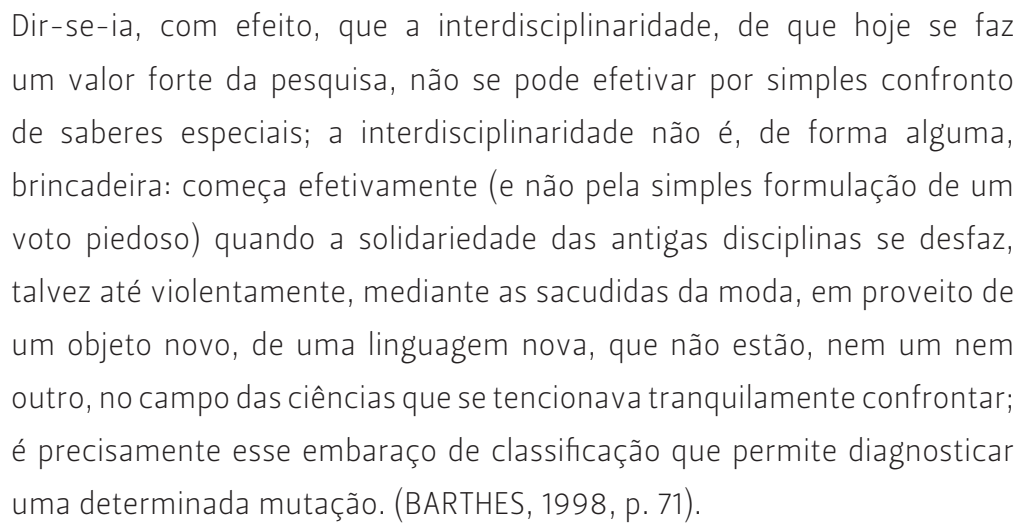

0 caminho da interdisciplinaridade mostra-se promissor porque, se a formação docente é processo contínuo, constituído pela amálgama entre a trajetória de vida e os referentes culturais e sociais, ela é, também, um processo de formação humana. Log’, no decorrer do percurso de formação e exercício profissional, ao professor devem ser oferecidas oportunidades para a mobilização de experiências que promovam o desenvolvimento das competências requeridas pela BNCC. Inúmeros podem ser os caminhos para isso e o acesso aos bens culturais e artísticos parece ser um deles. Explicando melhor: o professor leva para a sala de aula sua maneira de ser como pessoa, o que leu, o que estudou, suas crenças e contradições. 0 acesso a variados recursos artísticos e culturais pode contribuir para impulsionar competências, que, a depender do modo como serão significadas, favorecerão leituras de mundo subsidiárias a uma prática pedagógica melhor, porque embasada e articulada às demandas interdisciplinares existentes no mundo de hoje, à atuação cidadã e ao exercício crítico e autônomo de sua profissão. Assim, espera-se que a capacidade para a atuação interdisciplinar seja perpassada pelos vínculos estabelecidos com a cultura, em suas múltiplas possibilidades expressivas: música, teatro, literatura, dança, entre outras. 
Gatti e Barreto (2009), em estudo que identificou o perfil dos professores brasileiros, demonstraram que $10 \%$ deles provêm de lares de pais analfabetos. Esse percentual, se somado à taxa dos que têm pais que frequentaram a escola apenas até a $4^{\mathrm{a}}$. série do Ensino Fundamental, atinge a proporção de $50 \%$, o que constitui um indicador sobre a bagagem cultural das famílias desse grupo geracional. As autoras destacam que esses dados, se comparados aos fornecidos por Fanfani (2005) sobre a condição docente de professores da escola básica da Argentina, do Peru, do Brasil e do Uruguai, mostram diferenças ainda mais acentuadas entre o capital cultural dos professores brasileiros e o dos demais países.

Mas como o trabalho com recursos artísticos e culturais pode mobilizar no professor leituras de mundo interdisciplinares? Quando nos valemos, por exemplo, do estudo de Vidas secas, de Graciliano Ramos, inúmeros conhecimentos que envolvem a história, a geografia, a literatura, a gramática, a sociologia, a antropologia, a biologia, a arte, para enumerar apenas alguns deles, podem ser mobilizados. Isso tem o potencial de impulsionar o trabalho com outras e variadas competências relacionadas; por exemplo, a construção de projetos de vida baseados em discussões sobre a condição humana em uma sociedade de classes. Ou seja, trata-se de um processo de ensino e aprendizagem realizado em conexão com as demandas vigentes na sociedade contemporânea.

De igual forma, podemos discutir quantas competências, além da relacionada ao senso estético, podem ser mobilizadas durante o contato com as temáticas retratadas na obra de Sebastião Salgado. Quanto se pode aprender ao ouvir as composições de Chiquinha Gonzaga, ler sobre sua vida e sobre as condições em que sua obra foi composta, isto é, em um contexto de discriminação da mulher? Que competências a leitura de Quarto de despejo, de Carolina Maria de Jesus, pode mobilizar ao trabalhar a questão das diferenças sociais, relacionadas à situação da mulher pobre e negra no contexto brasileiro? Quanto se pode discutir sobre cultura e seus referentes ao se conhecer as produções do estilista Ronaldo Fraga?

Uma ação pedagógica organizada segundo essas bases se relaciona com um ativo processo de ensino e aprendizagem, que objetiva estimular os estudantes a fazerem perguntas, levantarem hipóteses, discutirem eventuais erros cometidos no decorrer do percurso de estudo e articularem o conhecimento mobilizado para outras situações que não as tratadas em sala de aula. Ou seja, processos de pensamento que implicam autonomia intelectual. No entanto, reiteramos, as inúmeras possibilidades de 
implementação da BNCC passam pela relação de interdependência entre a mobilização das competências por ela propostas e a formação docente. Se a BNCC anuncia o desejo por uma sociedade em que cada pessoa seja capaz, no contexto da escola ou da vida, de enfrentar problemas pessoais ou coletivos de forma assertiva e benéfica, é preciso empreender processos formativos que reconheçam que apenas os conteúdos escolares parecem não mais bastar para a formação das novas gerações. Esse é o desafio posto para a escola nos novos tempos, para que se evite o que Marin e Giovanni (2007) chamam de "falência do sistema escolar", causada pela inexistência de uma relação direta entre o conhecimento do professor e a aprendizagem do aluno. Embora, no referido estudo, as autoras tratem da expressão escrita de professores recém-formados para atuação como alfabetizadores, considerase aqui que suas conclusões são válidas para o âmbito de todas as questões de base colocadas para a educação escolar.

Em texto que discute a formação de professores e o papel da educação e da escola em nossa sociedade, Gatti (2013) discute que uma

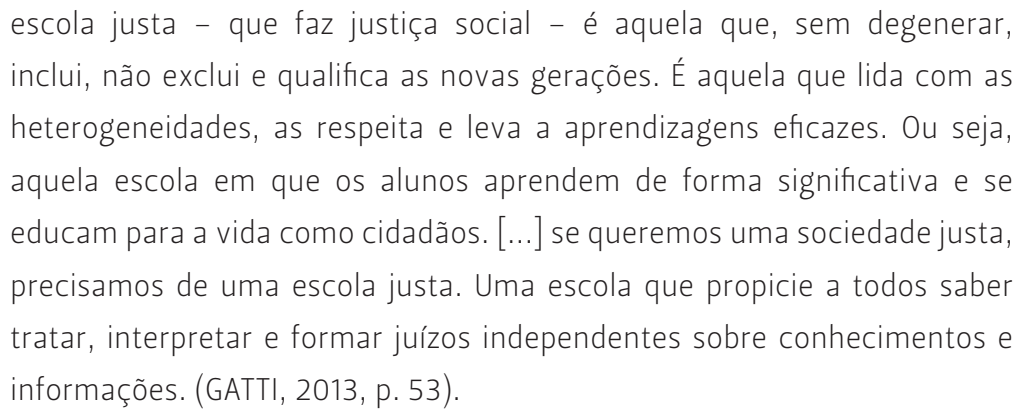

Para tanto, é necessário que os professores estejam preparados para levar os estudantes a apreender e mobilizar conhecimentos já produzidos, ao mesmo tempo em que formam-nos com valores necessários para a vida em sociedade. Prática pedagógica, ainda de acordo com Gatti (2013, p. 55), "por ser pedagógica, é ação política, de cidadania, comportando formas de ação guiadas por seus fundamentos, sejam filosóficos, sejam científicos. Implica fazer pensando e pensar fazendo, implica saber fazer e por que fazer". Assim, professores bem formados são profissionais capazes de empreender ações pedagógicas intencionais, com conhecimentos e instrumentos articulados às novas configurações sociais e às suas demandas e detentores de ideias e práticas educativas fecundas.

Um projeto educativo como o que aqui está sendo discutido se relaciona com políticas públicas educacionais que lidem com 
o fenômeno educativo de forma sistêmica e de acordo com a complexidade que o caracteriza: formando bem os professores, mas dando-Ihes também boas condições de trabalho, de jornada e salário compatível, além da realização de investimentos nas escolas e no trabalho lá desenvolvido.

Gatti (2010) sinalizou que a formação docente de caráter interdisciplinar é bem-sucedida em diversos países, mas encontra resistências no contexto brasileiro em razão da forte tradição disciplinar que marca nossa identidade como professores, sustentada pela visão cientificista do século XIX. Romper com esse ciclo é um desafio complexo e que implica uma mudança de mentalidades, como apontado por Cericato (2016), para quem

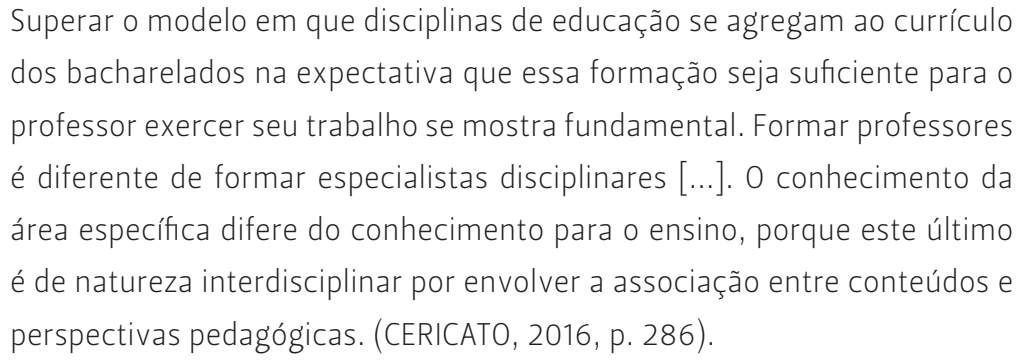

A autora destaca ainda que não se trata de desprezar os conhecimentos específicos, mas de escolher, em cada área, o que é importante que um professor saiba. Desse modo, em uma compreensão sistêmica do fenômeno, entende-se que mudanças na formação de professores envolvem, necessariamente, a criação de uma íntima articulação da formação inicial realizada nas universidades com as demandas da escola.

Destaca-se também que não se desmerece tudo o que o estudante pode aprender e mobilizar na relação estabelecida fora da escola com familiares, pares e, de modo geral, pessoas da comunidade; no entanto, ressalta-se que professores formados em uma perspectiva ativa, aberta, interdisciplinar e plural estarão em melhores condições para oferecer uma formação da mesma natureza aos estudantes, inspirando-os rumo a uma visão de mundo conectada com os desafios contemporâneos.

\section{O outro lado da questão}

Variadas críticas são dirigidas à BNCC, apesar de sua homologação pelo Conselho Nacional de Educação. Uma dessas críticas alega que a BNCC recebe influências do setor privado, representado por um empresariado organizado com o objetivo de tornar o Brasil competitivo internacionalmente, sendo necessário, 
para tanto, empreender um projeto de formação da juventude, sobretudo a pobre, vinculado ao mercado de trabalho. Nessa perspectiva, tal projeto se opõe a uma formação mais humana e capaz de integrar conhecimentos científicos e culturais. Além disso, considera-se também que, nos últimos anos, a escola tem se tornado um interessante nicho de mercado à medida em que, com o desenvolvimento do capitalismo, determinados espaços de lucratividade foram se esgotando. Assim, a reformulação dos currículos impulsionada pela BNCC acaba por movimentar um mercado de livros, apostilas e cursos de gestão e de formação de professores a custos interessantes para a geração de lucratividade.

Por falar em currículo, embora o Ministério da Educação dig̉a que a BNCC não é currículo, o fato é que na prática tal documento padroniza os conteúdos a serem aplicados em todas as escolas, deixando em segundo plano as diversidades locais de um país com dimensões continentais e enormes variações culturais. Outra crítica relacionada a esse mecanismo advoga que ele, além de prejudicar a diversidade de estratégias locais na formação dos estudantes, também impede as inovações metodológicas desenvolvidas pelas escolas, que passarão a ser padronizadas, o que, em última instância, acaba por desmoralizar o professor porque o desqualifica. A lógica estabelecida obriga, ainda, os professores a seguir os conteúdos estipulados pela BNCC pelo fato de serem vinculados às avaliações em larga escala, que, por sua vez, são vinculadas a sistemas de bonificação de professores e de certificação de escolas, correspondendo à lógica da meritocracia, ou seja, observa-se o gerencialismo empresarial sendo empregado na educação.

Gerenciar o processo de implementação da BNCC, no entanto, têm se mostrado um desafio. Para Castro (2018) o maior deles está na articulação entre as unidades federadas e seus municípios, sem a qual o sucesso da proposta pode ficar comprometido. 
Para a autora, a coordenação de ações entre os três níveis de governo, além da efetiva articulação entre cada estado e seus municípios, com prioridade à formação continuada dos professores, se faz imprescindível.

Diante do cenário exposto, uma última questão relevante deve ser destacada. Há quem diga que as universidades, sobretudo as públicas, resistirão em tomar as competências propostas pela BNCC como norteadoras dos processos formativos porque os cursos de formação de professores nessas instituições têm histórico de posicionamentos críticos. Ocorre, contudo, que conforme o censo do ensino superior de 2016, em termos quantitativos, a formação de professores é realizada, majoritariamente, por grupos de ensino superior particulares, que, embora em grande medida financiados pelo Estado, não atuam guiados pelos mesmos princípios que as universidades públicas. 0 cenário, ao que parece, indica que o debate em torno da questão ainda não se encerrou, mesmo após a aprovação da BNCC pelo CNE.

\section{Considerações finais}

Em educação não existem resultados rápidos - nesse campo, as mudanças são lentas e levam gerações para serem percebidas. No entanto, o discurso do empresariado diante da crise da educação, por ser pragmático, soa ágil. Na ânsia de resolver os problemas educacionais, projetos empresariais de gestão são transpostos para as escolas e multiplicam-se as avaliações que buscam controlar a prática escolar na expectativa de se alcançar os resultados prometidos. Os professores, por sua vez, sentem-se obrigados a colocar mais atenção nas avaliações do que nos processos de ensino. Instala-se um processo perverso que encontra ressonância em setores do poder público afeitos à lógica empresarial. Ocorre que a lógica da educação não pode ser regida pela do mercado. Os processos de aprendizagem devem ser cultivados pelo apreço ao conhecimento, que confere liberdade e autonomia ao indivíduo, o qual, compreendendo melhor o mundo por meio da formação que possui, pode contribuir com seu trabalho para o desenvolvimento da sociedade em que se insere.

Considera-se importante destacar que processos formativos são complexos e multifacetados e, por essa razão, a apresentação de um modelo único a ser seguido seria atitude ingênua. Buscouse apresentar aqui, portanto, uma alternativa ancorada na perspectiva da interdisciplinaridade, com consciência, porém, de que outras são possíveis. Essa escolha é interessante justamente 
por se contrapor à padronização, ou uniformização, de percursos formativos e por buscar construir caminhos que levem o professor ao pensamento crítico e ao cultivo da cultura geral, e não apenas à especialização. Tais premissas contribuem para formar um professor que, diferentemente do que prega uma visão utilitarista da educação, possa pensar sobre o contexto educacional de seu país posicionando-se criticamente a seu respeito. As escolhas docentes (tanto dos formadores de professores como dos profissionais em atuação na educação básica) nunca são, conforme as entendemos, plenas; no entanto, apesar de sempre relativas, ainda assim são autônomas porque pautadas por escolhas possíveis no âmbito profissional e sustentadas pela capacidade que cada professor possui de analisar as circunstâncias educacionais em que está envolvido tomando decisões sobre elas. Como tecer essa capacidade na ausência de sólidas experiências formativas?

Por fim, encerramos este texto acreditando que se é necessário educar as novas gerações, é necessário educar também os professores que educam as novas gerações, oferecendo-lhes experiências formativas condizentes com o que deles se espera. Defendemos um modelo formativo interdisciplinar, amparado em base cultural sólida que contribua para mobilizar competências que envolvem a articulação de conhecimentos específicos aos de domínio pedagógico, de modo que o professor não seja apenas um técnico no exercício de sua profissão, mas, sim, um profissional com autonomia e capaz de refletir sobre o contexto e os modos como realiza seu trabalho.

\section{REFERÊNCIAS BIBLIOGRÁFICAS}

BARTHES, Roland. O rumor da língua. Trad.: Mário Laranjeira. São Paulo: Brasiliense, 1998.

CASTRO, Maria Helena Guimarães. Desafios da implementação da BNCC. In: Castro, M.H.G; Callou, R. (coord). Educação em pauta: uma agenda para o país. Organização de Estados Ibero-americanos para a Educação, a Ciência e a Cultura, 2018. p. 53-65. Disponível em: <https://drive.google.com/ file/d/1lvy4w0WyeE0oaWxlltExC5ula1f08mgo/view>. Acesso em: 9 ago. 2018 
CERICATO, Itale L. A profissão docente em análise no Brasil: uma revisão bibliográfica. Revista Brasileira de Estudos Pedagógicos (online), Brasília, DF, v. 97, n. 246, p. 273-289, maio/ago. 2016. Disponível em: <http://www.scielo.br/pdf/ rbeped/v97n246/2176-6681-rbeped-97-246-00273.pdf>. Acesso em: $1^{\circ}$ ago. 2018.

CUNHA, Maria Isabel. O tema da formação de professores: trajetórias e tendências do campo na pesquisa e na ação. Educação e Pesquisa, São Paulo, v. 39, n. 3, p. 609-625, jul./ set. 2013. Disponível em: <http://www.scielo.br/pdf/ep/ v39n3/aop1096.pdf>. Acesso em: 10 ago. 2018.

FANFANI, Emilio T. La condición docente: análisis comparado de la Argentina, Brasil, Perú y Uruguai. Buenos Aires: Siglo XXI Editores, 2005.

GATTI, Bernardete; BARRETO, Elba S. Professores do Brasil: impasses e desafios. Brasília, DF: UNESCO, 2009. Disponível em: <http://unesdoc.unesco.org/ images/0018/001846/184682por.pdf>. Acesso em: 14 ago. 2018.

GATTI, Bernardete. Formação de professores no Brasil: características e problemas. Educação \& Sociedade, Campinas, v. 31, n. 113, p. 1355-1379, out./dez. 2010. Disponível em: <http://wWw.scielo.br/pdf/es/v31n113/16. pdf>. Acesso em: 14 ago. 2018.

GATTI, Bernardete. Educação, escola e formação de professores: políticas e impasses. Educar em Revista, Curitiba, n. 50, p. 51-67, out./dez. 2013. Disponível em: <http://www.scielo.br/pdf/er/n50/n50a05.pdf>. Acesso em: 14 ago. 2018.

MACEDO, Lino; FINI, Maria Inês. Uma análise do conceito de competências na BNCC. Pátio Ensino Médio, Profissional e Tecnológico, ano X, n. 37, p. 15-18, jun./ago. 2018.

MARIN, Alda Junqueira; GIOVANNI, Luciana Maria. Expressão escrita de concluintes de curso universitário para formar professores. Cadernos de Pesquisa, v. 37, n. 130, p. 15-41, jan./abr. 2007. Disponível em: <http://www.scielo.br/scielo. 
php? script $=$ sci_arttext $\&$ pid $=$ S0100 $-15742007000100003 \&$ In g=en\&nrm=iso\&tlng=pt>. Acesso em: 14 ago. 2018.

MEAD, Margaret. L'adolescente in una società primitiva. Firenze: Ed. Universitária, 1968.

NÓVOA, Antônio. Formação de professores e profissão docente. In: Os professores e sua formação. Lisboa: Dom Quixote, 1992. p. 15-33.

Recebido: 20/09/2018

Revisto: 15/11/2018

Aceito: $24 / 10 / 2018$ 